\title{
Timing and cue competition in conditioning of the nictitating membrane response of the rabbit (Oryctolagus cuniculus)
}

\author{
E. James Kehoe, ${ }^{1,4}$ Elliot A. Ludvig, ${ }^{2}$ and Richard S. Sutton ${ }^{3}$ \\ ${ }^{1}$ School of Psychology, University of New South Wales, Sydney 2052, Australia; ${ }^{2}$ Department of Mechanical and Aerospace \\ Engineering and Princeton Neuroscience Institute, Princeton University, Princeton, New Jersey 08544, USA; ${ }^{3}$ Department of \\ Computing Sciences, University of Alberta, Edmonton, T6G 2E8, Canada
}

\begin{abstract}
Rabbits were classically conditioned using compounds of tone and light conditioned stimuli (CSs) presented with either simultaneous onsets (Experiment 1) or serial onsets (Experiment 2) in a delay conditioning paradigm. Training with the simultaneous compound reduced the likelihood of a conditioned response (CR) to the individual CSs ("mutual overshadowing") but left CR timing unaltered. CR peaks were consistently clustered around the time of unconditioned stimulus (US) delivery. Training with the serial compound (CSA $\rightarrow$ CSB $\rightarrow$ US) reduced responding to CSB ("temporal primacy/information effect") but this effect was prevented by prior CSB $\rightarrow$ US pairings. In both cases, serial compound training altered CR timing. On CSA $\rightarrow$ CSB test trials, the CRs were accelerated; the CR peaks occurred after CSB onset but well before the time of US delivery. Conversely, CRs on CSB- trials were decelerated; the distribution of CR peaks was variable but centered well after the US. Timing on CSB- trials was at most only slightly accelerated. The results are discussed with respect to processes of generalization and spectral timing applicable to the cerebellar and forebrain pathways in eyeblink preparations.
\end{abstract}

The present experiments characterized the timing of eyeblink conditioned responses (CRs) in the rabbit during "cue competition" between two compounded stimuli (CSs) with either simultaneous onsets (Experiment 1) or serial onsets (Experiment 2) in advance of an unconditioned stimulus (US). The timing of CRs for a single CS has been well characterized across CS-US intervals ranging from a few hundred milliseconds in eyeblink conditioning in several species (Smith 1968; Claflin et al. 2005; Kehoe et al. 2008, 2009b) through tens of seconds for appetitive conditioning in rats and pigeons (Cheng and Roberts 1991; Church et al. 1994; Ludvig et al. 2007). In all cases, peak responding occurred around the time that the reinforcer had been presented, and the variability in peak responding has tended to be proportional to the stimulus-reinforcer interval (Gibbon 1977; Cheng and Roberts 1991; Church et al. 1994; Lejeune and Wearden 2006; Kehoe et al. 2009b).

Less is known about timing when a compound of CSs signals the US. For stimulus-reinforcer intervals in the 10-90-sec range, peak responding during a compound and its component stimuli remains centered around the reinforcer. This pattern occurs even when compound training produces cue competition effects, most notably overshadowing of one or both stimuli and blocking of acquisition to an added stimulus (Jennings and Kirkpatrick 2006; Jennings et al. 2007; McMillan and Roberts 2010). The one exception appeared in McMillan and Roberts (2010). There, pretraining of a relatively short stimulus blocked the appearance of a systematic peak in responding. Responding was uniform across stimulus duration.

The available findings from appetitive conditioning suggest that the mechanisms for timing in the 10-90-sec range are largely, although not wholly, separate from the mechanisms that govern cue competition. The present experiments were conducted to

\section{${ }^{4}$ Corresponding author}

E-mail ejameskehoe@gmail.com

Article is online at http://www.learnmem.org/cgi/doi/10.1101/lm.028183.112. test whether or not timing and cue competition can be separated behaviorally in aversive eyeblink conditioning and its time scale in the hundreds of milliseconds. The experiments used two manipulations that have consistently produced cue competition effects in the rabbit nictitating membrane (NM) preparation. Experiment 1 examined timing under conditions conducive to "mutual overshadowing," in which there are reductions in responding to both individual CSs after compound training (Mackintosh 1976; cf. Kehoe 1979, 1983, 1986; Kehoe and Schreurs 1986b). Experiment 2 concerned a type of temporal overshadowing that can occur when the onset of one stimulus (CSA) precedes a second stimulus (CSB) by a few hundred milliseconds during reinforced compound trials (CSA $\rightarrow \mathrm{CSB} \rightarrow \mathrm{US}$ ) (Kehoe 1979, 1983; Kehoe et al. 1979). When CSB is tested outside the context of CSA, an "information effect" appears: Responding to CSB is much reduced relative to both CSA and controls, even though CSB was contiguous to the US (Egger and Miller 1962).

In both experiments, the CSs were a tone $(1000-\mathrm{Hz}, 83-\mathrm{dB}$ SPL, C scale superimposed on a background level of $76 \mathrm{~dB}$ ) and a light (20-Hz flashing of the houselight), which have yielded similar rates of acquisition when trained singly (Kehoe 1986; Kehoe and Schreurs 1986b). In Experiment 1, both CS durations were $800 \mathrm{msec}$. In Experiment 2, the first stimulus (CSA) was $800 \mathrm{msec}$, and the second stimulus (CSB) was $400 \mathrm{msec}$. The tone and light stimuli were counterbalanced as CSA and CSB. On reinforced trials in both experiments, CS offset coincided with US onset. The US was a 50-msec, 3-mA, 50-Hz AC current delivered to the periorbital region. See Kehoe and Joscelyne (2005) for details of apparatus and preparation.

Statistical analyses controlled for capitalization on chance with a Bonferroni adjustment for nonorthogonal comparisons using the compound and its two components $(\alpha=0.05 / 3=0.017)$. The effect size $(d)$ for each comparison was the upper and lower limits of the 95\% confidence interval in $\sigma$ units (Bird 2004). Effect sizes of $0.2,0.5$, and 0.8 were regarded as small, medium, and large effect sizes, respectively (Cohen 1988). 
In Experiment 1, the rabbits were randomly split between compound tone + light $\rightarrow$ US training (TL,$+ n=12)$ and three single-stimulus subgroups that received, respectively, tone $\rightarrow$ US pairings $(\mathrm{T}+, n=4)$, light $\rightarrow$ US pairings $(\mathrm{L}+, n=4)$, and intermixed $\mathrm{T}+$ and $\mathrm{L}+$ pairings $(\mathrm{T}+/ \mathrm{L}+, n=4)$. The four groups were labeled as TL, T, L, and T/L, respectively. All groups received 14 sessions of training. For Groups TL, T, and L, each session contained 40 CS-US trials of the designated type, plus nonreinforced tests, specifically three TL - trials, three $\mathrm{T}$ - trials, and three $\mathrm{L}-$ trials. For Group T/L, there were $40 \mathrm{~T}+$ trials, $40 \mathrm{~L}+$ trials, three $\mathrm{TL}-$ trials, three $\mathrm{T}$ - trials, and three $\mathrm{L}-$ trials. The different types of trials were evenly distributed through a 90-min session. The tests were rare enough as to not distort the results (Kehoe and Schreurs 1986a).

Figure 1, top panel, shows the mean percentage CRs displayed by each group on $\mathrm{TL}-, \mathrm{T}-$, and $\mathrm{L}-$ trials, respectively. On the TL - tests, all the groups, except Group L, achieved asymptotic levels around 80\% CRs. Group L plateaued at around 60\% CRs, but this difference did not reach the adjusted level of significance, $F_{(1,20)}=5.78, P=0.026, d(0.08,1.16)$.

On $\mathrm{T}-$ trials, pronounced differences appeared. Groups $\mathrm{T} / \mathrm{L}$ and $\mathrm{T}$, which were trained with $\mathrm{T}+$ trials, reached mean levels around 90\% CRs. In contrast, Group TL responded significantly less, around $40 \%$, smaller $F_{(1,20)}=30.39, P<0.01, d(0.92,2.04)$. Group L, which did not receive any pairings of tone with the US, also showed little responding on $\mathrm{T}-$ trials, similar to Group TL, $P>0.05$.

On L- test trials, a complementary pattern appeared. Group TL showed significantly less responding than Group T/L and Group L, smaller $F_{(1,20)}=14.48, P<0.01, d(0.56,1.93)$, and about the same responding as Group T, $P>0.05$.

Group TL thus showed mutual overshadowing (cf. Kehoe 1986; Kehoe and Schreurs 1986b). Its responding on both Tand $\mathrm{L}-$ trials was less than that on $\mathrm{TL}-$ trials. Within Group TL, a comparison was conducted using the TL- trials vs. whichever individual stimulus ( $\mathrm{T}-$ or $\mathrm{L}-$ ) elicited the higher level of responding. Specifically, at the end of training (days 11-14), responding to the compound $(M=83 \%, \mathrm{SE}=9 \%)$ was significantly higher than that to the individual stimuli $(M=$ $43 \%, \mathrm{SE}=12 \%), F_{(1,20)}=19.57, P<0.01, d(0.60,1.68)$. In the other groups, the corresponding comparisons were not statistically significant, all $F^{\prime} \mathrm{s}<1$. Responding to the compound could be explained by whichever stimuli had been trained individually.

CR peak latency, as the index of timing, was the point of maximum NM closure on test trials relative to CS onset as measured on the nonreinforced test trials $(\mathrm{TL}-, \mathrm{T}-, \mathrm{L}-$ ). Figure 2 shows frequency distributions of the peak latencies aggregated over all days and all animals in each group.

Notwithstanding differences in levels of responding across trial types and groups, the peaks largely clustered around the time of the onset of the 50-msec US at $800 \mathrm{msec}$ after CS onset (Kehoe et al. 2008, 2009a,b, 2010). The one possible exception occurred in Group T/L. On its TL- test trials, its peaks often occurred around 100-200 msec before US onset. However, this possible summation failed to attain the adjusted level of significance. The mean peak latency in Group T/L on TL - trials $(M=$ $701 \mathrm{msec}$ ) did not differ significantly from either the mean on T- test trials $(M=848 \mathrm{msec}), F_{(1,20)}=4.42, P=0.048, d(0.01$, $1.9)$, or that on $\mathrm{L}-$ trials, $F_{(1,20)}=1.64, P>0.05, d(-0.75$, 0.31). A comparison of Group T/L with Group TL on its TL - tests $(M=834 \mathrm{msec})$ also failed to attain the adjusted level of significance, $F_{(1,20)}=5.31, P=0.030, d(0.08,1.66)$.

These findings are consistent with previous findings in which timing was preserved despite cue competition effects. This pattern of findings can be readily explained by a wide range of cue competition theories (e.g., Rescorla and Wagner 1972; Mackintosh 1975; Pearce and Hall 1980; Wagner 2008). Broadly speaking, these theories assume that, although the total amount

\section{Experiment 1}
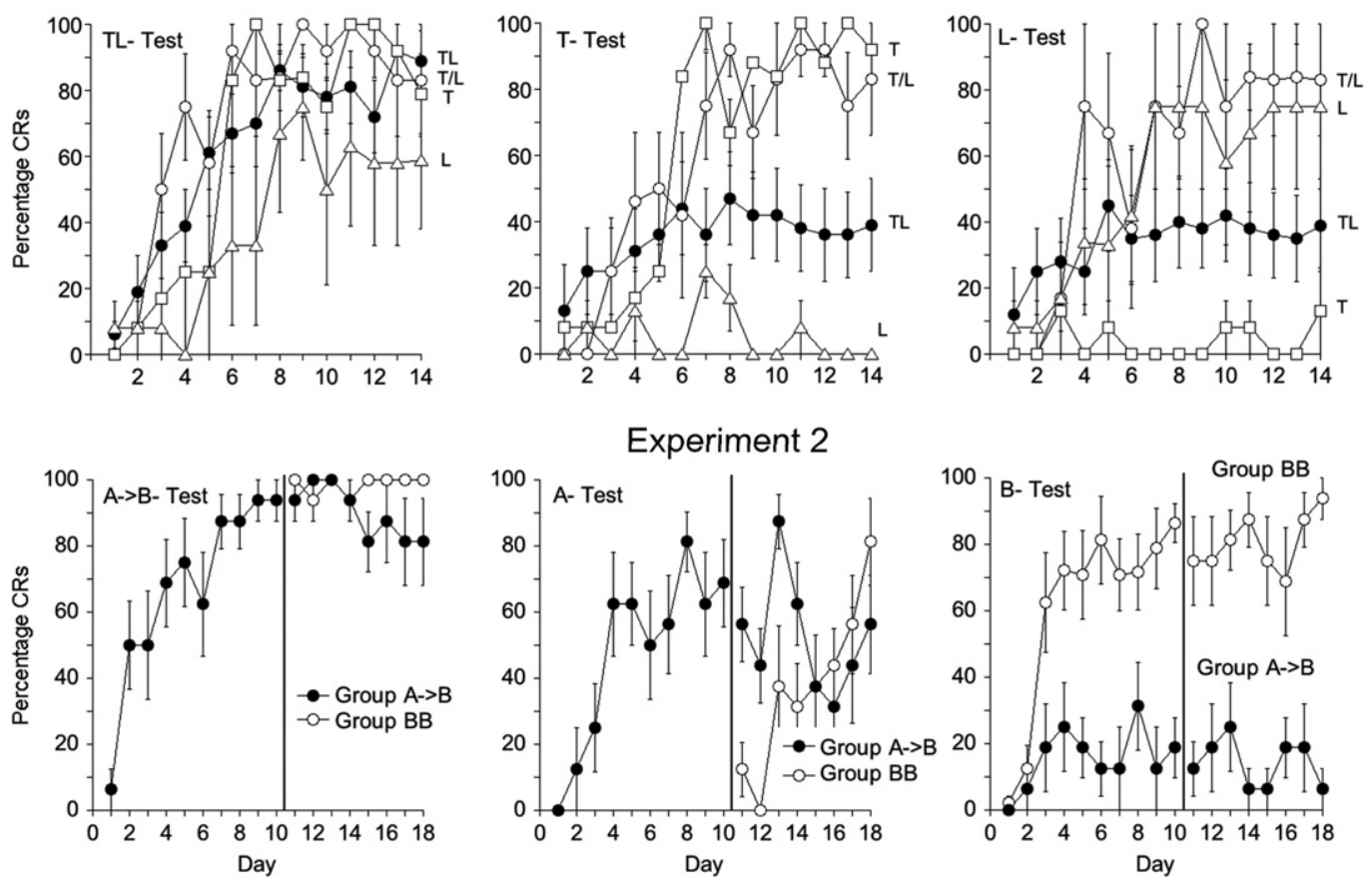

Figure 1. The mean percentage of CRs on test trials as a function of days in both experiments. For Experiment 2 , the vertical line between day 10 and day 11 indicates the transition between Phase 1 and Phase 2. Error bars indicate \pm 1 standard error of the mean. 

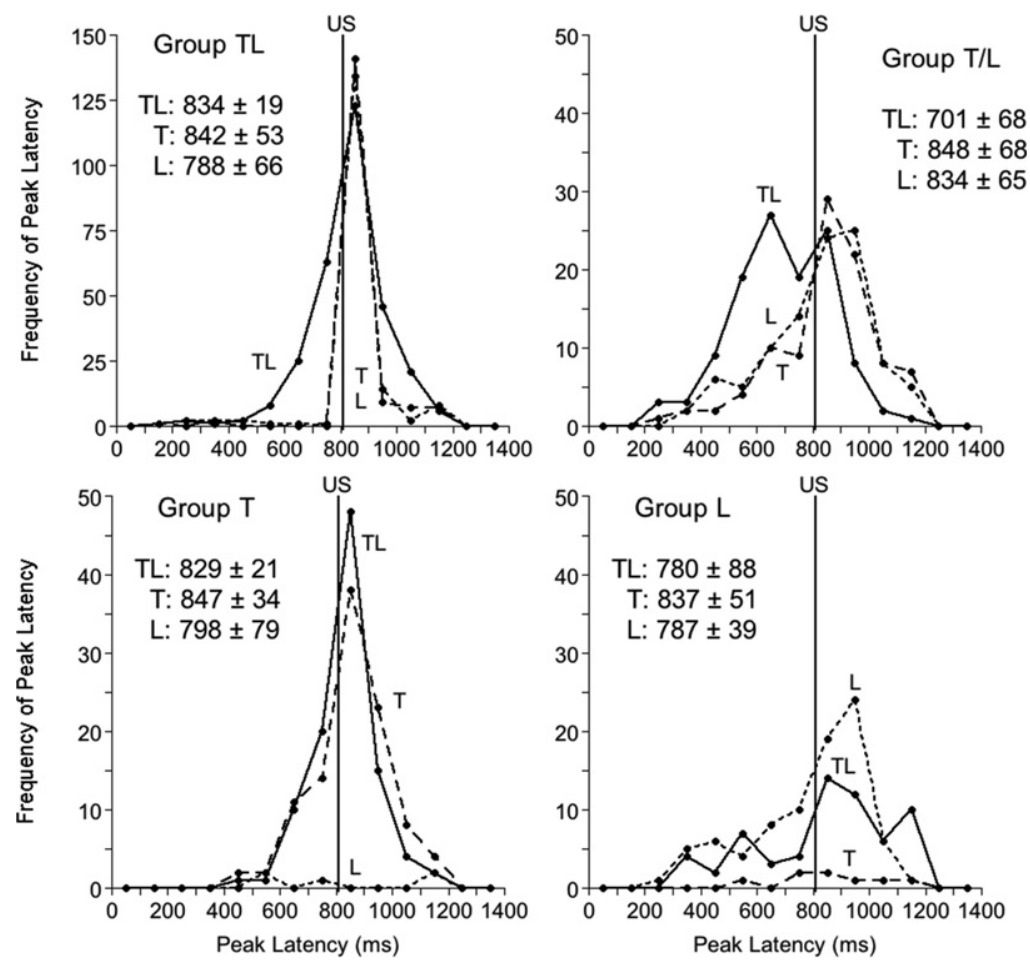

Figure 2. Frequency distributions of CRs during test trials in Experiment 1. Note that the ordinates have been adjusted to accommodate the larger number of rabbits in Group TL relative to the other three groups. Each panel also lists the mean and standard error for the peak latency on each type of test trial.

of learning for each element of a compound is limited by tradeoffs in associative and/or attentional processes, learning proceeds according to the same rules that operate in pairing of a single CS with the US. The clustering of CR peaks around the time of the US in all training and test conditions suggests the acquisition of timing follows the same rules inside or outside a simultaneous compound.

Any change in stimulus conditions from training to testing might yield a generalization decrement. For example, in rabbit eyeblink preparations, training with a 500-msec CS-US interval at one tone frequency and testing with other frequencies has produced progressive increases in peak latency, virtually doubling the peak latency (Garcia et al. 2003). Changes in other features of a single CS, for example its duration, can produce small increases in peak latency. Truncation of a 400-msec delay CS and extension of a 50-msectrace CS has on occasion increased CR peak latencies by a maximum of $100 \mathrm{msec}$ (Kehoe and Napier 1991), but not always (Kehoe et al. 2009a).

In this context, the present findings indicate that, for compounds of stimuli from different sensory modalities (tone, light), neither subtracting elements from a compound CS (Group TL) nor adding nonconditioned elements to an established CS (Groups T and $\mathrm{L}$ ) yields differences between TL- tests vs. tests of T- and L-, which would be indicative of a generalization decrement in CR timing. Combining established CSs (Group T/L) produced a small, albeit nonsignificant, acceleration in peak latency more indicative of a summation of associative strengths than a generalization decrement (cf. Kehoe et al. 1994).

Experiment 2 had two groups. One group $(A \rightarrow B)$ received 18 sessions of training. Each session contained $60 \mathrm{CSA} \rightarrow \mathrm{CSB} \rightarrow \mathrm{US}$ trials, interspersed with two $\mathrm{CSA} \rightarrow \mathrm{CSB}-$ tests, two CSA - tests, and two CSB - tests. The other group (B Blocker [BB]) received
$>80 \%$ CRs.

training with $\mathrm{CSB} \rightarrow$ US pairings on days 1-10. Each session contained 60 $\mathrm{CSB} \rightarrow$ US trials interspersed with six CSB tests. This initial training provided a comparison condition for demonstrating an information effect in Group $\mathrm{A} \rightarrow \mathrm{B}$. Subsequently, on days 11-18, Group BB's sessions were identical to those of Group A $\rightarrow$ B. This serial compound training tested two alternative hypotheses: (1) The initial CSB $\rightarrow$ US pairings would establish CSB as a predictor of the US, reverse the information effect, and block CR acquisition to CSA (Egger and Miller 1962, 1963) and (2) adding CSA may engage a second-order conditioning process, which in turn may cause CSA to capture associative strength from CSB yielding an information effect (Sutton and Barto 1981; Kehoe et al. 1987; Cole and McNally 2007).

The lower panels of Figure 1 show the mean percentage $\mathrm{CRs}$ on $\mathrm{CSA} \rightarrow$ $\mathrm{CSB}-, \mathrm{CSA}-$, and CSB - test trials, respectively. In Phase 1 (days 1-10), a pronounced information effect appeared. Specifically, responding on CSB - trials in Group $\mathrm{A} \rightarrow \mathrm{B}$ diverged to less than half the level seen in Group BB, $F_{(1,14)}=$ $27.49, P<0.01, d(0.25,0.59)$. However, an information effect did not emerge in Group BB when CSA was added to training in Phase 2 (days 11-18). Responding on CSB trials in Group BB remained

Responding on CSA - trials in Group A $\rightarrow$ B showed acquisition that reached levels hovering around $50 \%$, albeit with considerable variability. In Phase 2, Group BB also showed variable acquisition of CRs to CSA. The level of responding to CSA in Group BB rose above that of Group $A \rightarrow B$, although not significantly on days 16,17 , or 18 , all $P$ 's $>0.10$. Thus, the prior $\mathrm{CSB} \rightarrow$ US training failed to block CR acquisition to CSA, which broadly agrees with the previous observations of very weak blocking of an added CSA (Kehoe et al. 1987). Similarly, in fear conditioning of rats, Cole and McNally (2007) found that blocking in fear conditioning was diminished when a blocked stimulus in a simultaneous compound was lengthened to create a serial compound.

Responding on CSA $\rightarrow$ CSB trials in Group $A \rightarrow B$ reached high, stable levels, significantly greater than those in either CSA - or CSB - tests, smaller $F_{(1,7)}=21.63, P<0.01, d(0.29$, 0.88). In Phase 2 for Group BB, responding on CSA $\rightarrow$ CSB - trials appeared higher than the level of responding to CSB that had been trained in Phase 1. This difference, however, did not reach the corrected level of significance, $F_{(1,7)}=7.86, P=0.026, d(0.12,1.39)$.

Figure 3 shows frequency distributions of the CR peak latencies on nonreinforced test trials in each phase. More than $90 \%$ of CRs in both groups showed a single pronounced peak. The CRs on $\mathrm{CSA} \rightarrow \mathrm{CSB}$ - trials in both groups generally peaked well before the time of US onset but after the time of CSB onset. In Group A $\rightarrow B$, the peak distributions in Phase 1 initially showed some bimodality, but settled into a unimodal distribution centered 120 msec before US onset in Phase $2(M=680 \mathrm{msec})$. In Group BB, the peaks during $\mathrm{CSA} \rightarrow \mathrm{CSB}-$ trials occurred another $100 \mathrm{msec}$ earlier $(M=577 \mathrm{msec})$. This difference between the two groups in Phase 2 was statistically significant, $F_{(1,14)}=8.91, P<0.01, d$ $(0.32,1.92)$. The acceleration in the $\mathrm{CR}$ peaks on $\mathrm{CSA} \rightarrow \mathrm{CSB}-$ 

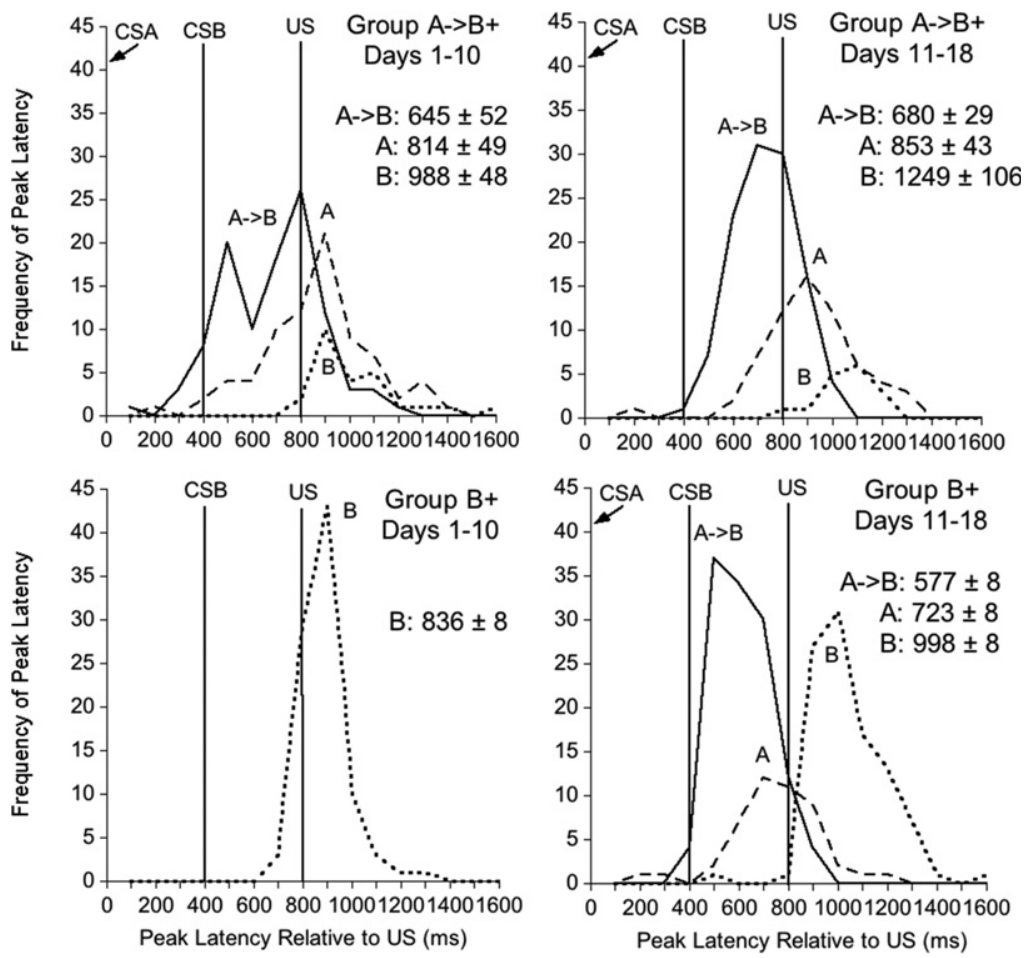

Figure 3. Frequency distributions of CRs during test trials during Phase 1 (days 1-10) and Phase 2 (days 11-18). The times of CSA onset, CSB onset, and US onset are indicated by vertical lines. Each panel also lists the mean and standard error for the peak latency relative to CSA onset on each type of test trial. For expressing the means relative to CSB onset, subtract $400 \mathrm{msec}$.

trials in both groups was also significant relative to the CR peaks on CSA trials, $F_{(1,14)}=151.62, P<0.01, d(0.92,1.30)$ and CSBtrials $(1,11)=67.45, P<0.01, d(2.70,4.67)$. The degrees of freedom are reduced in the $\mathrm{CSB}-$ comparison because three rabbits in Group $\mathrm{A} \rightarrow \mathrm{B}$ never responded on a CSB - test.

CR timing on CSA trials showed, at most, only slight acceleration. In Group $A \rightarrow B$, the CRs on CSA trials peaked after the time of US onset in both Phase $1(M=814 \mathrm{msec})$ and Phase $2(M=$ $853 \mathrm{msec}$ ). In Group BB, the CRs on CSA trials tended to peak slightly before US onset $(M=723 \mathrm{msec})$, but in comparison to Group $\mathrm{A} \rightarrow \mathrm{B}$ this acceleration did not attain the corrected level of significance, $F_{(1,14)}=6.64, P=0.022, d(0.15,1.65)$. When exposure to CSA was roughly equated by comparing Group BB in Phase 2 to Group $A \rightarrow B$ in Phase 1, no difference was discernible, $F<1$.

On CSB - trials in Group $\mathrm{A} \rightarrow \mathrm{B}$, the few CRs that did occur peaked well after the US $(M=988 \mathrm{msec}$ in Phase $1, M=$ 1249 msec in Phase 2). In Group BB, CR timing on CSB- trials was well defined in Phase 1 . The distribution had a single pronounced mode located immediately after US onset. However, when $\mathrm{CSA} \rightarrow \mathrm{CSB} \rightarrow \mathrm{US}$ training was introduced, peak latencies on CSB - trials became more variable and longer, increasing significantly to $998 \mathrm{msec}, F_{(1,7)}=46.76, P<0.01, d(1.75,3.61)$, similar to the peak latencies on CSB - trials in Group $\mathrm{A} \rightarrow \mathrm{B}(M=$ $1249 \mathrm{msec}), F_{(1,11)}=3.28, P=0.10, d(-0.30,3.09)$.

In summary, in both groups there was strong synergistic effect of the CSA $\rightarrow \mathrm{CSB} \rightarrow$ US training. On CSA $\rightarrow$ CSB trials, the CRs often peaked several hundred milliseconds prior to US onset, while the CRs on CSA - test trials and CSB - test trials peaked later, generally after the time of US onset. In the case of Group BB, a deceleration and variability in peaks on CSB- trials occurred only after the introduction of CSA $\rightarrow \mathrm{CSB} \rightarrow$ US training, after ini- tial CSB $\rightarrow$ US training had produced CR peaks tightly packed around the US.

The acceleration in CR timing seen on CSA $\rightarrow$ CSB trials appeared to be a unique result of serial compound training and not of the simultaneous compound training. Recall that, in Experiment 1, Group TL's peaks on types of test trial were all clustered around the time of US onset. The mean peak latency on TL - trials was $834 \mathrm{msec}$, which had a 95\% confidence interval of 790878 msec. In contrast, Group $\mathrm{A} \rightarrow \mathrm{B}$ 's mean peak latency on its serial compound trials across days 1-14 was 652 msec with a confidence interval of $575-728 \mathrm{msec}$, which did not overlap that of the simultaneous compound on $\mathrm{TL}-$ trials.

While CRs on CSA $\rightarrow$ CSB trials were accelerated relative to those of TL- trials, the CRs on CSA - trials were clustered near the time of the US in the same way as they typically are in eyeblink conditioning with single CSs. Specifically, the mean peak latency on tests of the 800-msec CSA in Group CSA $\rightarrow$ CSB yielded a mean peak latency of $820 \mathrm{msec}$, with a confidence interval of 732-908 msec. Similarly, averaging across $\mathrm{T}-$ and $\mathrm{L}-$ trials in Group TL yielded a mean peak latency of 815 msec with a confidence interval of 731-899 msec.

Given the locus of $\mathrm{CR}$ peaks near the US on CSA - trials, the acceleration of CR peaks on CSA $\rightarrow$ CSBtrials appears to have depended on the presence of CSB in the compound. Yet, the CR peaks on CSB - trials showed deceleration rather than acceleration. The mean CR peak latency on CSB- trials averaged across days 1-14 day was $1012 \mathrm{msec}$ with a confidence interval of 920-1105 msec.

The deceleration plus the low likelihood of a CR on CSB - trials in Group $\mathrm{A} \rightarrow \mathrm{B}$ may have arisen from a generalization decrement that occurred when CSB was tested outside the context provided by CSA, which preceded and overlapped CSB (Wickens 1959; Kehoe 1979). However, the results of Group BB make a generalization decrement hypothesis difficult to sustain. Recall that initial $\mathrm{CSB} \rightarrow \mathrm{US}$ training produced a high level of responding to CSB with CR peaks clustered around the time of US onset $(M=$ $811 \mathrm{msec}$; confidence interval $777-845 \mathrm{msec}$ ). Thus, overall CR likelihood and CR timing were well established to CSB outside the context of the CSA. Even if CSB was encoded differently inside the $\mathrm{CSA} \rightarrow \mathrm{CSB} \rightarrow$ US compound, the CSB - tests should have retrieved the initial CR with its original timing. The maintenance of a high level of responding on $\mathrm{CSB}-$ trials during $\mathrm{CSA} \rightarrow \mathrm{CSB} \rightarrow$ US training indicates that CSB was still encoded as it had been during $\mathrm{CSB} \rightarrow$ US training. Thus, the increase in CR peak latency on CSB - test trials in Group BB cannot be easily labeled as a generalization decrement.

This set of results also presents a challenge to the prevailing class of computational models used to explain both timing and cue competition in eyeblink conditioning. According to these models, there is a spectral timing process in which each CS is encoded by an array of asynchronous microstimuli that provide a distinctive pattern at each time point (Desmond and Moore 1988; Grossberg and Schmajuk 1989; Gluck et al. 1990; Buonomano and Mauk 1994; Machado 1997; Kirkpatrick and 
Church 1998; Buhusi and Schmajuk 1999; Vogel et al. 2003; Buhusi and Meck 2005; Ludvig et al. 2008, 2009; Lepora et al. 2010). The associative strengths of these microstimuli are adjusted via an error-correction rule by which the microstimuli generated by each CS compete with both each other and those of any concurrent CSs (Rescorla and Wagner 1972; Sutton and Barto 1981). Thus, there can be mutual overshadowing among both microstimuli and nominal CSs, which would nevertheless leave the timing of CRs intact.

This type of model can explain the results of Experiment 1, in which the CR peaks were consistently aligned with the US across wide variations in response levels, especially the mutual overshadowing in Group TL. By the same token, the key results of Experiment 2 cannot be readily explained by these models. First, the displacement of CR peaks in opposite directions on $\mathrm{CSA} \rightarrow \mathrm{CSB}-$ and $\mathrm{CSB}$ - trials would not appear to be easily generated by the available models. For example, simulations of $\mathrm{CSA} \rightarrow \mathrm{CSB} \rightarrow$ US training using our microstimulus model left the CR peaks aligned with the US for the compound stimulus, with only a slight acceleration for the CSA (cf. Fig. 7C in Ludvig et al. 2012; details are available on request). Second, with regard to the information effect, most of the available computational models predict the reverse outcome. CSB should overshadow CSA-, because the microstimuli generated by CSB- will generally be more intense at the time of US delivery and accordingly capture more associative strength than those generated by CSA. Some success in explaining the information effect has been achieved using real-time error correction rules. They update associative strengths continuously, not only at the end of the experimenter-defined trial (Sutton and Barto 1990; Schultz and Dickinson 2000; Waelti et al. 2001; Ludvig et al. 2008, 2012). The activation level from one moment is constantly compared to the activation level at the next moment as the basis for the "error" term. Thus, one CS (or its microstimuli) can gain associative strength by reliably predicting subsequent CSs, not just the US. These real-time rules explain the information effect, because CSA progressively absorbs the associative strength gained by CSB. However, these rules predict incorrectly for Group BB that the information effect should appear even when serial compound training is preceded by $\mathrm{CSB} \rightarrow$ US training (Sutton and Barto 1981; Kehoe et al. 1987; Cole and McNally 2007).

An improved understanding of CR timing and cue competition in serial as well as in simultaneous compounds could lie along two routes, specifically modeling of CS interactions and delineation of the neural pathways for CS interactions.

First, computational models generally assume that the encodings of each CS only influence each other through the competitive error-correction process. However, compounded CSs may interact at other stages of processing (e.g., Kehoe and Gormezano 1980; Bellingham et al. 1985; Pearce 1994; Harris 2006; Wagner 2008). For computational purposes, layered networks provide a framework for representing a variety of interactions that effectively change the elements competing for associative strength (e.g., Kehoe 1988). Along this line of thought, Buhusi and Schmajuk (1999) have combined a spectral timing mechanism into a layered network. Although they simulated conditional control of responding in serial compounds, our reading of their model does not reveal how it might reproduce the results of Experiment 2, specifically, the alterations in CR timing and divergence between groups in the occurrence of the information effect.

Among the known neural pathways for eyeblink conditioning, the two most likely sites at which CS encodings may interact are the cortex of the cerebellum and/or the forebrain, specifically the hippocampus and prefrontal cortex. The basic pathways for timing eyeblink CRs reside in the cerebellar cortex (Buonomano and Mauk 1991; Perrett et al. 1993; Moore and Choi 1997; Mauk et al. 2000), especially its Purkinje cells (Ito 1984; Steuber and Willshaw 2004; Jirenhed et al. 2007; Svensson et al. 2010; Jirenhed and Hesslow 2011) and granule cells (Medina and Mauk 2000). These cerebellar pathways interact with the hippocampus and prefrontal cortex (Weiss and Disterhoft 2011). The hippocampus plays a role in the processing of simultaneous and serial compounds in eyeblink conditioning (Daum et al. 1991; Green and Woodruff-Pak 2000; Bellebaum and Daum 2004; Wolf et al. 2012). Lesions there reduce cue competition but not CR acquisition to single CSs (Solomon 1977). With regard to CR timing, hippocampal lesions lead to earlier CR initiation, though the CR peak has remained aligned with the time of US delivery (Port et al. 1986; Christiansen and Schmajuk 1992). For future recording and interventions in both areas, the divergent timing of $\mathrm{CRs}$ on $\mathrm{CSA} \rightarrow \mathrm{CSB}$ - trials vs. $\mathrm{CSB}$ - trials should provide a distinctive behavioral and possibly neural signature.

\section{Acknowledgments}

The apparatus and procedures were approved under Australian ethics legislation. Preparation of this manuscript was supported by Alberta Ingenuity and the Informatics Circle of Research Excellence (iCORE), both part of Alberta Innovates-Technology Futures (Canada).

\section{References}

Bellebaum C, Daum I. 2004. Effects of age and awareness on eyeblink conditional discrimination learning. Behav Neurosci 118: 1157-1165

Bellingham WP, Gillette-Bellingham K, Kehoe EJ. 1985. Summation and configuration in patterning schedules with the rat and rabbit. Anim Learn Behav 13: 152-164.

Bird KD. 2004. Analysis of variance via confidence intervals, pp. 9-10. Sage, London.

Buhusi CV, Meck WH. 2005. What makes us tick? Functional and neural mechanisms of interval timing. Nat Rev Neurosci 6: 755-765.

Buhusi CV, Schmajuk NA. 1999. Timing in simple conditioning and occasion setting: A neural network approach. Behav Processes 45: 33-57.

Buonomano DV, Mauk MD. 1991. Neural network based on the circuitry of the cerebellum simulates the timing of motor responses. Soc Neurosci Abstr 17: 870 .

Buonomano DV, Mauk MD. 1994. Neural network model of the cerebellum: Temporal discrimination and the timing of motor responses. Neural Comput 6: 38-55.

Cheng K, Roberts WA. 1991. Three psychological principles of timing in pigeons. Learn Motiv 22: 112-128.

Christiansen BA, Schmajuk NA. 1992. Hippocampectomy disrupts the topography of the rat eyeblink response during acquisition and extinction of classical conditioning. Brain Res 595: 206-214.

Church RM, Meck WH, Gibbon J. 1994. Application of scalar timing theory to individual trials. J Exp Psychol Anim Behav Process 20: 135-155.

Claflin DI, Garrett T, Buffington ML. 2005. A developmental comparison of trace and delay eyeblink conditioning in rats using matching interstimulus intervals. Dev Psychobiol 47: 77-88.

Cohen J. 1988. Statistical power analysis for the behavioral sciences, 2nd ed. Erlbaum, Hillsdale, NJ.

Cole S, McNally GP. 2007. Temporal-difference prediction errors and Pavlovian fear conditioning: Role of NMDA and opioid receptors. Behav Neurosci 121: 1043-1052.

Daum I, Channon S, Polkey CE, Gray JA. 1991. Classical conditioning after temporal lobe lesions in man: Impairment in conditional discrimination. Behav Neurosci 105: 396-408.

Desmond JE, Moore JW. 1988. Adaptive timing in neural networks: The conditioned response. Biol Cybern 58: 405-415.

Egger DM, Miller NE. 1962. Secondary reinforcement in rats as a function of information value and reliability of the stimulus. J Exp Psychol 64: $174-184$.

Egger MD, Miller NE. 1963. When is a reward reinforcing? An experimental study of the information hypothesis. JComp Physiol Psychol 56: 132-137.

Garcia KS, Mauk MD, Weidemann G, Kehoe EJ. 2003. Covariation of alternative measures of responding in rabbit (Oryctolagus cuniculus) eyeblink conditioning during acquisition training and tone generalization. Behav Neurosci 117: 292-303.

Gibbon J. 1977. Scalar expectancy theory and Weber's Law in animal timing. Psychol Rev 84: 279-325. 
Gluck MA, Reifsnider ES, Thompson RF. 1990. Adaptive signal processing and the cerebellum: Models of classical conditioning and VOR adaptation. In Neuroscience and Connectionist theory (ed. MA Gluck, DE Rumelhart), pp. 131-185. Erlbaum, Hillsdale, NJ.

Green JT, Woodruff-Pak DS. 2000. Eyeblink classical conditioning: Hippocampal formation is for neutral stimulus associations as cerebellum is for association-response. Psychol Bull 126: 138-158.

Grossberg S, Schmajuk NA. 1989. Neural dynamics of adaptive timing and temporal discrimination during associative learning. Neural Netw 2: 79-102.

Harris JA. 2006. Elemental representations of stimuli in associative learning. Psychol Rev 113: 584-605.

Ito M. 1984. The cerebellum and neural control. Raven Press, New York.

Jennings DM, Kirkpatrick K. 2006. Interval duration effects on blocking in appetitive conditioning. Behav Processes 71: 318-329.

Jennings DJ, Bonardi C, Kirkpatrick K. 2007. Overshadowing and stimulus duration. J Exp Psychol Anim Behav Process 33: 464-475.

Jirenhed D-A, Hesslow G. 2011. Time course of classically conditioned Purkinje cell response is determined by initial part of conditioned stimulus. J Neurosci 31: 9070-9074.

Jirenhed D-A, Bengtsson F, Hesslow G. 2007. Acquisition, extinction, and reacquisition of a cerebellar cortical memory trace. J Neurosci 27: 2493-2502.

Kehoe EJ. 1979. The role of CS-US contiguity in classical conditioning of the rabbit's nictitating membrane response to serial stimuli. Learn Motiv 10: $23-38$

Kehoe EJ. 1983. CS-US contiguity and CS intensity in conditioning of the rabbit's nictitating membrane response to serial compound stimuli. J Exp Psychol Anim Behav Process 9: 307-319.

Kehoe EJ. 1986. Summation and configuration in conditioning of the rabbit's nictitating membrane response to compound stimuli. J Exp Psychol Anim Behav Process 12: 186-195.

Kehoe EJ. 1988. A layered network model of associative learning: Learning-to-learn and configuration. Psychol Rev 95: 411-433.

Kehoe EJ, Gormezano I. 1980. Configuration and combination laws in conditioning with compound stimuli. Psychol Bull 87: 351-378.

Kehoe EJ, Joscelyne A. 2005. Temporally specific extinction of conditioned responses in the rabbit (Oryctolagus cuniculus) nictitating membrane preparation. Behav Neurosci 119: 1011-1022.

Kehoe EJ, Napier RM. 1991. In the blink of an eye: Real-time stimulus factors in delay and trace conditioning of the rabbit's nictitating membrane response. Q J Exp Psychol 43B: 257-277.

Kehoe EJ, Schreurs BG. 1986a. Compound conditioning of the rabbit's nictitating membrane response: Test trial manipulations. Bull Psychon Soc 24: $79-81$.

Kehoe EJ, Schreurs BG. 1986b. Compound-component differentiation as a function of CS-US interval and CS duration in the rabbit's nictitating membrane response. Anim Learn Behav 14: 144-154.

Kehoe EJ, Gibbs CM, Garcia E, Gormezano I. 1979. Associative transfer and stimulus selection in classical conditioning of the rabbit's nictitating membrane response to serial compound CSs. J Exp Psychol Anim Behav Process 5: $1-18$.

Kehoe EJ, Schreurs BG, Graham P. 1987. Temporal primacy overrides prior training in serial compound conditioning of the rabbit's nictitating membrane response. Anim Learn Behav 15: 455-464.

Kehoe EJ, Horne AJ, Horne PS, Macrae M. 1994. Summation and configuration between and within sensory modalities in classical conditioning of the rabbit. Anim Learn Behav 22: 19-26.

Kehoe EJ, Ludvig EA, Dudeney JE, Neufeld J, Sutton RS. 2008. Magnitude and timing of nictitating membrane movements during classical conditioning of the rabbit (Oryctolagus cuniculus). Behav Neurosci 122: $471-476$.

Kehoe EJ, Ludvig EA, Sutton RS. 2009a. Magnitude and timing of CRs in delay and trace classical conditioning of the nictitating membrane response of the rabbit (Oryctolagus cuniculus). Behav Neurosci 123: $1095-1101$.

Kehoe EJ, Olsen KN, Ludvig EA, Sutton RS. 2009b. Scalar timing varies with response magnitude in classical conditioning of the nictitating membrane response of the rabbit (Oryctolagus cuniculus). Behav Neurosci 123: $212-217$.

Kehoe EJ, Ludvig EA, Sutton RS. 2010. Timing in trace conditioning of the nictitating membrane response of the rabbit (Oryctolagus cuniculus): Scalar, nonscalar, and adaptive features. Learn Mem 17: 600-604.

Kirkpatrick K, Church RM. 1998. Are separate theories of conditioning and timing necessary? Behav Processes 44: 163-182.

Lejeune H, Wearden JH. 2006. Scalar properties in animal timing: Conformity and violations. Q J Exp Psychol 59: 1875-1908.
Lepora N, Porrill J, Yeo C, Dean P. 2010. Sensory prediction or motor control? Application of Marr-Albus type models of cerebellar function to classical conditioning. Front Comput Neurosci 4: 140.

Ludvig EA, Conover K, Shizgal P. 2007. The effects of reinforcer magnitude on timing in rats. J Exp Anal Behav 87: 201-218.

Ludvig EA, Sutton RS, Kehoe EJ. 2008. Stimulus representation and the timing of reward-prediction errors in models of the dopamine system. Neural Comput 20: 3034-3054.

Ludvig EA, Sutton RS, Verbeek EL, Kehoe EJ. 2009. A computational model of hippocampal function in trace conditioning. Adv Neural Inf Process Syst 21: $993-1000$.

Ludvig EA, Sutton RS, Kehoe EJ. 2012. Evaluating the TD model of classical conditioning. Learn Behav 40: 305-319.

Machado A. 1997. Learning the temporal dynamics of behavior. Psychol Rev 104: $241-265$.

Mackintosh NJ. 1975. A theory of attention: Variation in the associability of stimuli with reinforcement. Psychol Rev 82: 276-298.

Mackintosh NJ. 1976. Overshadowing and stimulus intensity. Anim Learn Behav 4: 186-192.

Mauk MD, Medina JF, Nores WL, Ohyama T. 2000. Cerebellar function: Coordination, learning or timing? Curr Biol 10: R522-R525.

McMillan N, Roberts WA. 2010. The effects of cue competition on timing in pigeons. Behav Processes 84: 581-590.

Medina JF, Mauk MD. 2000. Computer simulation of cerebellar information processing. Nat Neurosci 3: 1205-1211.

Moore JW, Choi J-S. 1997. Conditioned response timing and integration in the cerebellum. Learn Mem 4: 116-129.

Pearce JM. 1994. Similarity and discrimination: A selective review and a connectionist model. Psychol Rev 101: 587-607.

Pearce JM, Hall G. 1980. A model for Pavlovian learning: Variations in the effectiveness of conditioned but not of unconditioned stimuli. Psychol Rev 87: 532-552.

Perrett SP, Ruiz BP, Mauk MD. 1993. Cerebellar cortex lesions disrupt learning-dependent timing of conditioned eyelid responses. J Neurosci 13: $1708-1718$

Port RL, Romano AG, Patterson MM. 1986. Stimulus duration discrimination in the rabbit: Effects of hippocampectomy on discrimination and reversal learning. Physiol Psychol 14: 124-129.

Rescorla RA, Wagner AR. 1972. A theory of Pavlovian conditioning: Variations in the effectiveness of reinforcement and nonreinforcement. In Classical conditioning II (ed. AH Black, WF Prokasy), pp. 64-99. Appleton-Century-Croft, New York.

Schultz W, Dickinson A. 2000. Neuronal coding of prediction errors. Annu Rev Neurosci 23: 473-500.

Smith MC. 1968. CS-US interval and US intensity in classical conditioning of the rabbit's nictitating membrane response. J Comp Physiol Psychol 66: $679-687$.

Solomon PR. 1977. Role of hippocampus in blocking and conditioned inhibition of the rabbit's nictitating membrane response. J Comp Physiol Psychol 91: 407-417.

Steuber V, Willshaw D. 2004. A biophysical model of synaptic delay learning and temporal pattern recognition in a cerebellar Purkinje cell. J Comput Neurosci 17: 149-164.

Sutton RS, Barto AG. 1981. Toward a modern theory of adaptive networks: Expectation and prediction. Psychol Rev 88: 135-171.

Sutton RS, Barto AG. 1990. Time-derivative models of Pavlovian reinforcement. In Learning and computational neuroscience (ed. M Gabriel, JW Moore), pp. 497-537. MIT Press, Cambridge, MA.

Svensson P, Jirenhed D-A, Bengtsson F, Hesslow G. 2010. Effect of conditioned stimulus parameters on timing of conditioned Purkinje cell responses. J Neurophysiol 103: 1329-1336.

Vogel EH, Brandon SE, Wagner AR. 2003. Stimulus representation in SOP: II. An application to inhibition of delay. Behav Processes 62: 27-48.

Waelti P, Dickinson A, Schultz W. 2001. Dopamine responses comply with basic assumptions of formal learning theory. Nature 412: 43-48.

Wagner AR. 2008. Evolution of an elemental theory of Pavlovian conditioning. Learn Behav 36: 253-265.

Weiss C, Disterhoft JF. 2011. Exploring prefrontal cortical memory mechanisms with eyeblink conditioning. Behav Neurosci 125: 318-326.

Wickens DD. 1959. Conditioning to complex stimuli. Am Psychol 14: $180-188$.

Wolf OT, Bauser DS, Daum I. 2012. Eyeblink conditional discrimination learning in healthy young men is impaired after stress exposure. Psychophysiology 49: 164-171.

Received August 16, 2012; accepted in revised form November 27, 2012. 


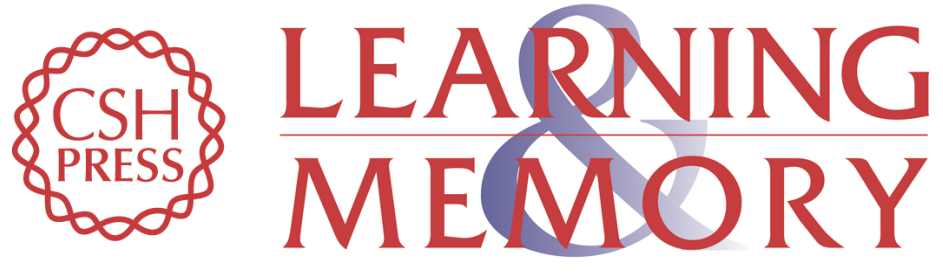

\section{Timing and cue competition in conditioning of the nictitating membrane response of the rabbit ( Oryctolagus cuniculus)}

E. James Kehoe, Elliot A. Ludvig and Richard S. Sutton

Learn. Mem. 2013, 20:

Access the most recent version at doi:10.1101/lm.028183.112

References This article cites 70 articles, 5 of which can be accessed free at:

http://learnmem.cshlp.org/content/20/2/97.full.html\#ref-list-1

License

Email Alerting Receive free email alerts when new articles cite this article - sign up in the box at the Service top right corner of the article or click here. 